Typeset using jjap.cls $<$ ver.1.0.1 $>$

\title{
Characterization of Al-Based Insulating Films Fabricated by Phys- ical Vapor Deposition
}

Masahide Nakakuki, Akihiro Shiono, Isao Kobayashi, Noriaki Tajima, Tomohiko Yamakami, Rinpei Hayashibe, Katsuya Abe, Kiichi Kamimura*, Motoki Obata ${ }^{1}$, and Mitsunori MiYamoto ${ }^{1}$

Faculty of Engineering, Shinshu University, 4-17-1 Wakasato, Nagano 380-8553, Japan

${ }^{1}$ Citizen Fine Tech Co., Ltd., 4107-5 Miyota, Kitasaku, Nagano 389-0295, Japan

(Received

A novel submount substrate with high thermal conductivity for optoelectronic devices is proposed. The substrate is fabricated by depositing an Al-based insulating film on a copper substrate. AlN films were deposited by RF reactive sputtering using an $\mathrm{Al}$ target $(5 \mathrm{~N})$ in a gas mixture of $\mathrm{Ar}$ and $\mathrm{N}_{2} \cdot \mathrm{Al}_{2} \mathrm{O}_{3}$ films were deposited by oxygen-ion-assisted electron beam (EB) evaporation. Many conductive paths were detected in the AlN films. These defects were introduced in the AlN film during a photolithography process for fabricating electrode patterns because the alkaline developer dissolved the film. An Al$\mathrm{OH}$ peak in Fourier transform infrared spectroscopy (FT-IR) spectra suggested that the $\mathrm{Al}(\mathrm{OH})_{3}$ formation was one of the reasons for the presence of conductive paths in the AlN film. In the case of $\mathrm{Al}_{2} \mathrm{O}_{3}$ films, no conducting path was detected in electrical measurements, and no marked change in surface morphology was observed in scanning electron microscopy (SEM) images, after treatment with the alkaline developer. The $\mathrm{Al}_{2} \mathrm{O}_{3} / \mathrm{Cu}$ structure is a candidate for the novel submount substrate with high thermal conductivity.

KEYWORDS: AIN, $\mathrm{Al}_{2} \mathrm{O}_{3}$, submount, reactive sputtering, electron beam evaporation

\footnotetext{
*E-mail address: kamimur@shinshu-u.ac.jp
} 


\section{Introduction}

Recently, the power of the laser diode (LD) has been increasing markedly, because of the requirements of optoelectronic applications with high speed and high recording density for optical disks such as digital versatile disk recordable (DVD-R) disks. Thus, the higher thermal conductivity of the submount substrate is required for high-power LD and light-emitting diode (LED) applications.

Aluminum nitride $(\mathrm{AlN})$ is the best material for the submount substrate because of its superior properties, such as high thermal conductivity $[260 \mathrm{~W} /(\mathrm{m} \cdot \mathrm{K})]$, high breakdown voltage $(15 \mathrm{kV} / \mathrm{mm})$, high resistivity $\left(10^{14} \Omega \cdot \mathrm{cm}\right)^{1)}$, and its thermal expansion coefficient being similar to that of $\mathrm{GaAs}^{2)}$. Thus, AlN is also used as surface passivation films of semiconductor devices and insulating films ${ }^{3-6)}$.

Carbon or metal materials must be used in order to obtain a thermal conductivity higher than that of AlN. However, C materials are not applicable to the submount substrate because of the fragility of graphite and the expensiveness of diamond. On the other hand, metal materials have no insulating property.

In this paper, we propose an $\mathrm{AlN}$ or $\mathrm{Al}_{2} \mathrm{O}_{3}$ film $/ \mathrm{Cu}$ substrate structure fabricated by physical vapor deposition (PVD) as a novel submount substrate. This structure is considered to be a submount substrate with good characteristics of both the insulating properties of an Al-based insulating film and the high thermal conductivity of $\mathrm{Cu}[400$ $\mathrm{W} /(\mathrm{m} \cdot \mathrm{K})]$.

\section{Experimental Procedure}

The AlN thin films were deposited on $\mathrm{Cu}$ film/glass substrates by sputtering in highpurity $\operatorname{Ar}(99.9999 \%)$ and $\mathrm{N}_{2}(99.9999 \%)$ atmosphere using the magnetron reactive sputtering system shown in Fig. 1. Here, the $\mathrm{Cu}$ film/glass substrate were fabricated by sputter-depositing the $\mathrm{Cu}$ film on the glass substrate. The RMS surface roughness of the $\mathrm{Cu}$ film/glass substrate was $1.8 \mathrm{~nm}$. The preferred orientation of the $\mathrm{Cu}$ film was (111) in the X-ray diffraction (XRD) pattern. The pure aluminum target was 6 inches in diameter and its purity was $99.999 \%$. The Al target was presputtered for $15 \mathrm{~min}$ by closing the target shutter. During the presputtering RF power and $\mathrm{Ar}+\mathrm{N}_{2}$ pressure were kept at 
$850 \mathrm{~W}$ and $0.5 \mathrm{~Pa}$, respectively. Ar and $\mathrm{N}_{2}$ were introduced into the chamber after the chamber was evacuated down to $4 \times 10^{-4} \mathrm{~Pa}$. The total gas flow rate of the gas mixture of $\operatorname{Ar}(7 \mathrm{sccm})$ and $\mathrm{N}_{2}(3 \mathrm{sccm})$ was maintained at $10 \mathrm{sccm}$ using mass flow controllers. The substrate temperature was maintained at $300{ }^{\circ} \mathrm{C}$. The sputtering pressure was 0.5 Pa. Under these conditions, the RF power was varied from 250 to $900 \mathrm{~W}$.

The $\mathrm{Al}_{2} \mathrm{O}_{3}$ thin films were deposited on $\mathrm{Cu}$ film/glass and $\mathrm{Cu}$ bulk substrates by electron beam (EB) evaporation using an $\mathrm{Al}_{2} \mathrm{O}_{3}$ powder source as shown in Fig. 2. The base pressure of the chamber was $9 \times 10^{-4} \mathrm{~Pa}$. The deposition pressure was $1.2 \times 10^{-2} \mathrm{~Pa}$ due to $\mathrm{O}_{2}$ gas introduction from an ion gun.

In our previous study, the $\mathrm{Al}_{2} \mathrm{O}_{3}$ thin films were also deposited by $\mathrm{RF}$ sputtering. However, the deposition rate was very low (about $1 \mathrm{~nm} / \mathrm{min}$ ) because of the oxidization of the $\mathrm{Al}$ target. On the other hand, the growth rate of the $\mathrm{Al}_{2} \mathrm{O}_{3}$ thin films deposited by $\mathrm{EB}$ evaporation was rather high with a value of about $50 \mathrm{~nm} / \mathrm{min}$.

It was observed from XRD patterns that the preferred orientation of the AlN thin films was (0002) and $\mathrm{Al}_{2} \mathrm{O}_{3}$ thin films were amorphous. In this paper, we focus on the insulating properties of the film and the crystalline structure is not discussed in detail because the film crystallinity is not important for the submount application. The film thicknesses of $\mathrm{AlN}$ and $\mathrm{Al}_{2} \mathrm{O}_{3}$ were both $0.5 \mu \mathrm{m}$. Au/Ti electrodes $(0.1 \mu \mathrm{m} \mathrm{Au}+0.05 \mu \mathrm{m} \mathrm{Ti})$ were fabricated on samples for Current - Voltage measurements by a photolithography process. Field-emission scanning electron microscopy (FE-SEM) was used to observe the microstructure of the film surface. The film thickness and surface roughness were measured using a profilometer. The composition mapping of the $\mathrm{Al}_{2} \mathrm{O}_{3}$ film surface was investigated by an energy-dispersive X-ray (EDX) component attached to FE-SEM.

\section{Results and Discussion}

Table I shows the electrical characteristics of the AlN/Cu structure deposited on the glass substrate with varying RF power. The upper electrode was formed with sputterdeposited Au/Ti film using the photolithographic lift-off method. The AlN film under the electrode was immersed in an NMD-3 developer for $2.5 \mathrm{~min}$. Here, yield ratio is defined as the ratio of the number of electrodes with resistivity higher than $10^{10} \Omega \cdot \mathrm{cm}$ to the total 
number of measured electrodes. No apparent relationship could observed between surface roughness and RF power. In all the samples, the yield ratio of $100 \%$ was not achieved. This means that conductive areas were present in the AlN film.

Martin $^{7)}$ and Heslop ${ }^{8)}$ reported that the AlN thin film dissolved in water or alkaline solution. Thus, the effect of water or the alkaline developer NMD-3 is discussed. Figure 3 shows that the surface morphology of AlN films dipped in water or NMD-3 for 2.5 min. The percentage in the figure shows the yield ratio. In these measurements, Al electrodes were fabricated on the AlN film by vacuum evaporation through the metal mask without photolithography. It was confirmed that the AlN films dissolved in the NMD-3 developer. This resulted in a decrease in the yield ratio, because the deposition of metal electrodes caused the formation of current paths along the pinhole, which was formed in the AlN film by the reaction with NMD-3.

Figure 4 shows the FT-IR spectra of the AlN films deposited on $\mathrm{Si}(001)$ with varying $\mathrm{RF}$ power. The Al-OH peak was detected at around $1100 \mathrm{~cm}^{-1}$ in all the samples. The surface and grain boundaries of the AlN film seem to have reacted with $\mathrm{H}_{2} \mathrm{O}$ in the air to form $\mathrm{Al}(\mathrm{OH})_{3}$ when the sample was taken out from the reaction chamber. Voigy and Sokolowski ${ }^{9)}$ reported that the formation of $\mathrm{Al}(\mathrm{OH})_{3}$ in AlN deteriorated its insulating properties. Thus, the result suggests that the $\mathrm{Al}(\mathrm{OH})_{3}$ formation is one of the reasons for the poor insulating properties of our AlN films.

To address the poor properties of the AlN films originating from dissolution in the alkaline developer, the $\mathrm{Al}_{2} \mathrm{O}_{3}$ films were applied to an insulating film instead of $\mathrm{AlN}$. The $\mathrm{Al}_{2} \mathrm{O}_{3}$ films have a strong corrosion resistance against water or alkaline solution and their properties are similar to those of AlN. Table II shows the electrical properties of the $\mathrm{Al}_{2} \mathrm{O}_{3}$ film/Cu structures. Here, the RMS surface roughness of the $\mathrm{Cu}$ film/glass substrate and $\mathrm{Cu}$ bulk were 1.8 and $12.4 \mathrm{~nm}$, respectively. The electrodes of these samples were fabricated by the photolithography process. In the $\mathrm{Al}_{2} \mathrm{O}_{3} / \mathrm{Cu}$ film/glass substrate samples, a yield ratio of $100 \%$ was obtained. Thus, it was confirmed that the $\mathrm{Al}_{2} \mathrm{O}_{3}$ film did not dissolve in the NMD-3 developer. However, in the $\mathrm{Al}_{2} \mathrm{O}_{3} / \mathrm{Cu}$ bulk substrate samples, the yield ratio was only $12.5 \%$. This poor yield ratio seems to correlate with the surface roughness. 
Figure 5 shows surface SEM images of the $\mathrm{Al}_{2} \mathrm{O}_{3}$ film/Cu film/glass structure and $\mathrm{Al}_{2} \mathrm{O}_{3} / \mathrm{Cu}$ bulk structure. The scratches originating from the surface of the $\mathrm{Cu}$ substrate were found on the surface of the $\mathrm{Al}_{2} \mathrm{O}_{3} / \mathrm{Cu}$ bulk structure.

Figure 6 shows the results of elemental mapping measurements in the $\mathrm{Al}_{2} \mathrm{O}_{3} / \mathrm{Cu}$ bulk sample. Only the $\mathrm{Cu}$ peak was detected on the scratches, instead of $\mathrm{O}$ and $\mathrm{Al}$ peaks. This means that the step coverage of the $\mathrm{Al}_{2} \mathrm{O}_{3}$ film is not enough to cover the scratches on the $\mathrm{Cu}$ bulk surface. Thus, it is suggested that the electrode film penetrated these scratches, and the electrodes and $\mathrm{Cu}$ substrate shorted.

\section{Conclusions}

AlN and $\mathrm{Al}_{2} \mathrm{O}_{3}$ films were deposited on $\mathrm{Cu}$ substrates by PVD and their electrical properties were characterized. The AlN insulating films were found to be difficult to apply to the photolithography process because of dissolution in the alkaline developer. It was found that to enhance the $\mathrm{Al}_{2} \mathrm{O}_{3} / \mathrm{Cu}$ structure fabricated by $\mathrm{EB}$ evaporation, the step coverage must be improved or the $\mathrm{Cu}$ bulk substrate must be planarized. The $\mathrm{Al}_{2} \mathrm{O}_{3}$ insulating film/Cu substrate configuration is suggested to be applicable to the novel submount substrate with high thermal conductivity.

\section{Acknowledgement}

This work was partially supported by The Foundation for Technology Promotion of Electronic Circuit Board. 


\section{References}

1) W. M. Yim, E. J. Stofko, P. J. Zanzucchi, J. I. Pankove, M. Ettenberge, and S. L. Gilbert: J. Appl. Phys. 44 (1973) 292.

2) W. M. Yim and R. J. Paff: J. Appl. Phys. 45 (1974) 1456.

3) J. Hwang, W. Schaff, B. Green, H. Cha, and L. Eastman: Solid-State Electron. 48 (2004) 363.

4) C. Men, Z. Xu, Z. An, X. Xie, M. Zhang, and C. Lin: Phys. B 324 (2002) 229.

5) W. Smetana and R. Reicher: Sens. Actuators A 58 (1997) 213.

6) V. Mortet, A. Vasin, and M. Djouadi: Surf. Coat. Technol. 176 (2003) 88.

7) F. Martin: Proc. IEEE Ultrason. Symp. 1, 2004, p. 169.

8) R. B. Heslop: Inorganic Chemistry (Elsevier, Amsterdam, 1976) p. 341.

9) M. Voigy and M. Sokolowski: Mater. Sci. Eng. B 109 (2004) 99. 


\section{Figure captions}

Fig. 1. Schematic diagram of the sputtering system.

Fig. 2. Schematic diagram of the electron beam evaporation system.

Fig. 3. Surface SEM images of AlN films: (a) with no treatments, (b) dipped in water for $2.5 \mathrm{~min}$, and (c) dipped in NMD-3 for 2.5 min. Yield ratios for the samples (a)-(c) were $100 \%, 97 \%$, and $80 \%$, respectively.

Fig. 4. FT-IR spectra of the AlN films deposited on $\mathrm{Si}(001)$ at various RF powers.

Fig. 5. Surface SEM images of (a) an $\mathrm{Al}_{2} \mathrm{O}_{3} / \mathrm{Cu}$ film/glass substrate, (b) an $\mathrm{Al}_{2} \mathrm{O}_{3} / \mathrm{Cu}$ bulk substrate, (c) a $\mathrm{Cu}$ film/glass substrate, and (d) a $\mathrm{Cu}$ bulk substrate.

Fig. 6. EDX mapping of the $\mathrm{Al}_{2} \mathrm{O}_{3} / \mathrm{Cu}$ bulk sample for elements of (a) $\mathrm{O}$, (b) $\mathrm{Al}$, and (c) $\mathrm{Cu}$. 
Table I. Electrical characteristics of $\mathrm{AlN} / \mathrm{Cu}$ structure.

\begin{tabular}{|c|c|c|c|c|c|}
\hline RF power (W) & 250 & 500 & 550 & 750 & 900 \\
\hline Breakdown field $(\mathrm{kV} / \mathrm{mm})$ & - & $11-30$ & $7-18$ & $6-14$ & - \\
\hline Yield ratio (\%) & 0 & 63 & 64 & 36 & 0 \\
\hline RMS Surface roughness (nm) & 10 & 6 & 4.5 & 8 & 11 \\
\hline
\end{tabular}


Table II. Electrical properties of $\mathrm{Al}_{2} \mathrm{O}_{3} / \mathrm{Cu}$ substrate.

\begin{tabular}{|c|c|c|}
\hline Substrate & Cu film/glass & $\mathrm{Cu}$ bulk \\
\hline Breakdown field $(\mathrm{kV} / \mathrm{mm})$ & $40-116$ & 50 \\
\hline Yield ratio $(\%)$ & 100 & 12.5 \\
\hline RMS Surface roughness $(\mathrm{nm})$ & 4.3 & 11.2 \\
\hline
\end{tabular}


Fig. 1

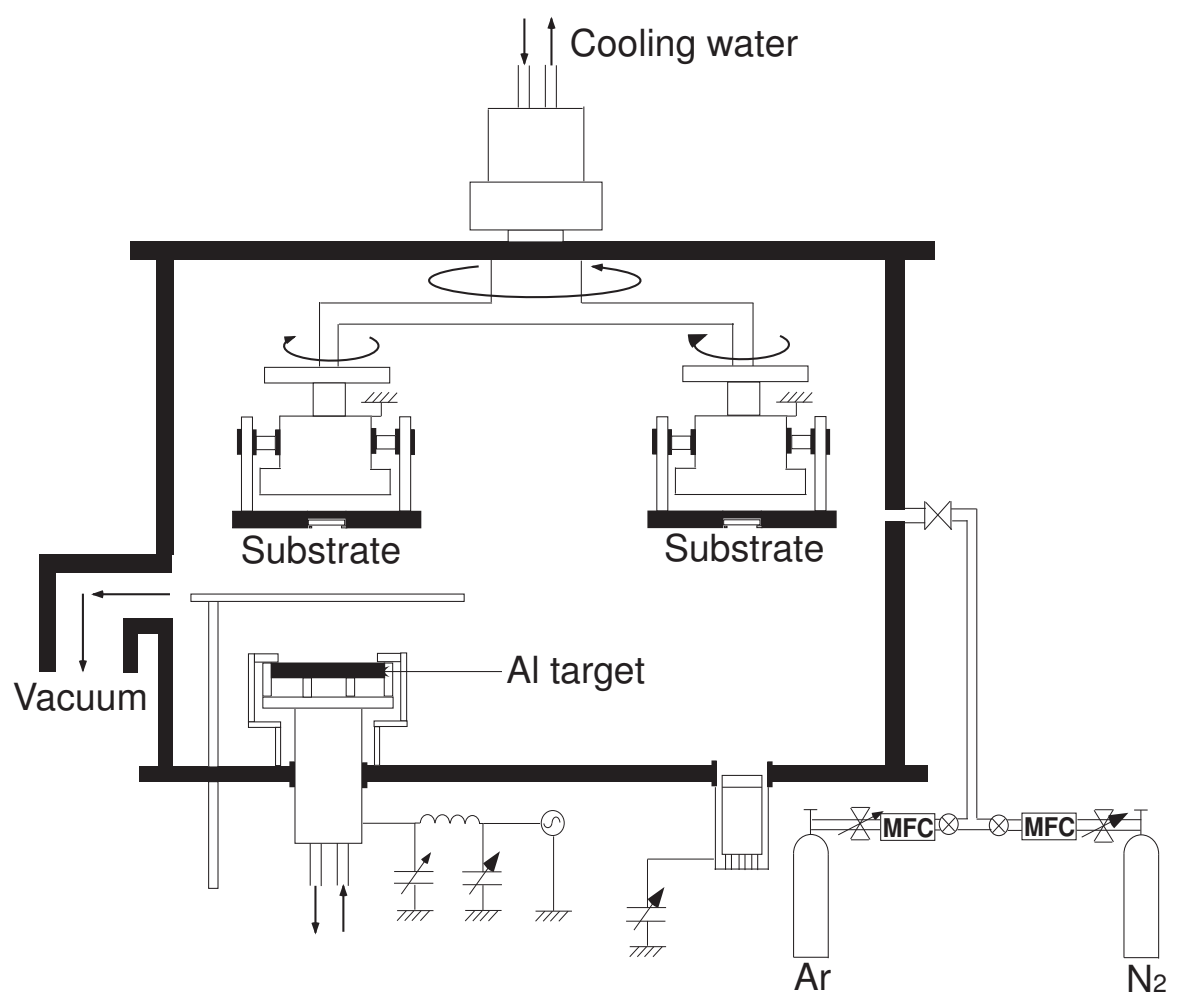


Fig. 2

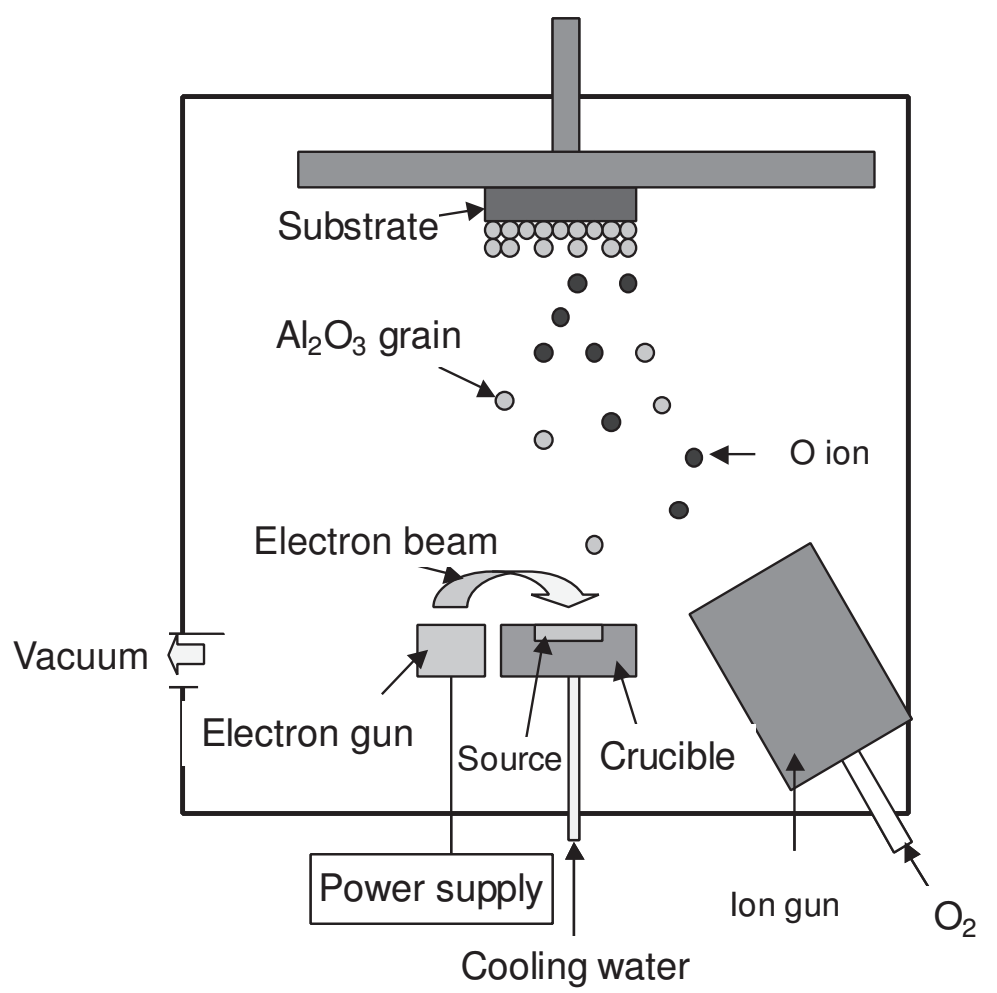


Fig. 3

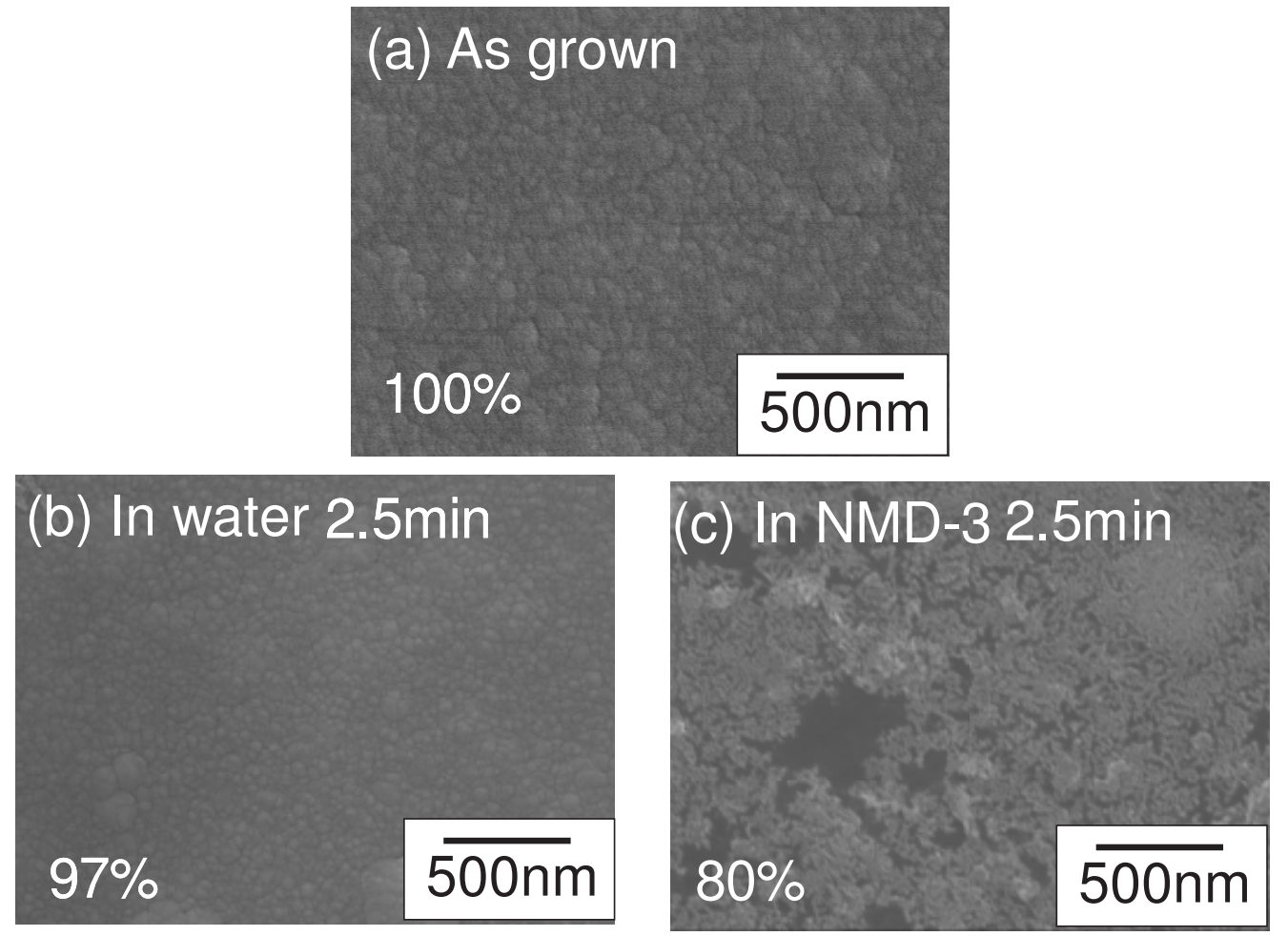


Fig. 4

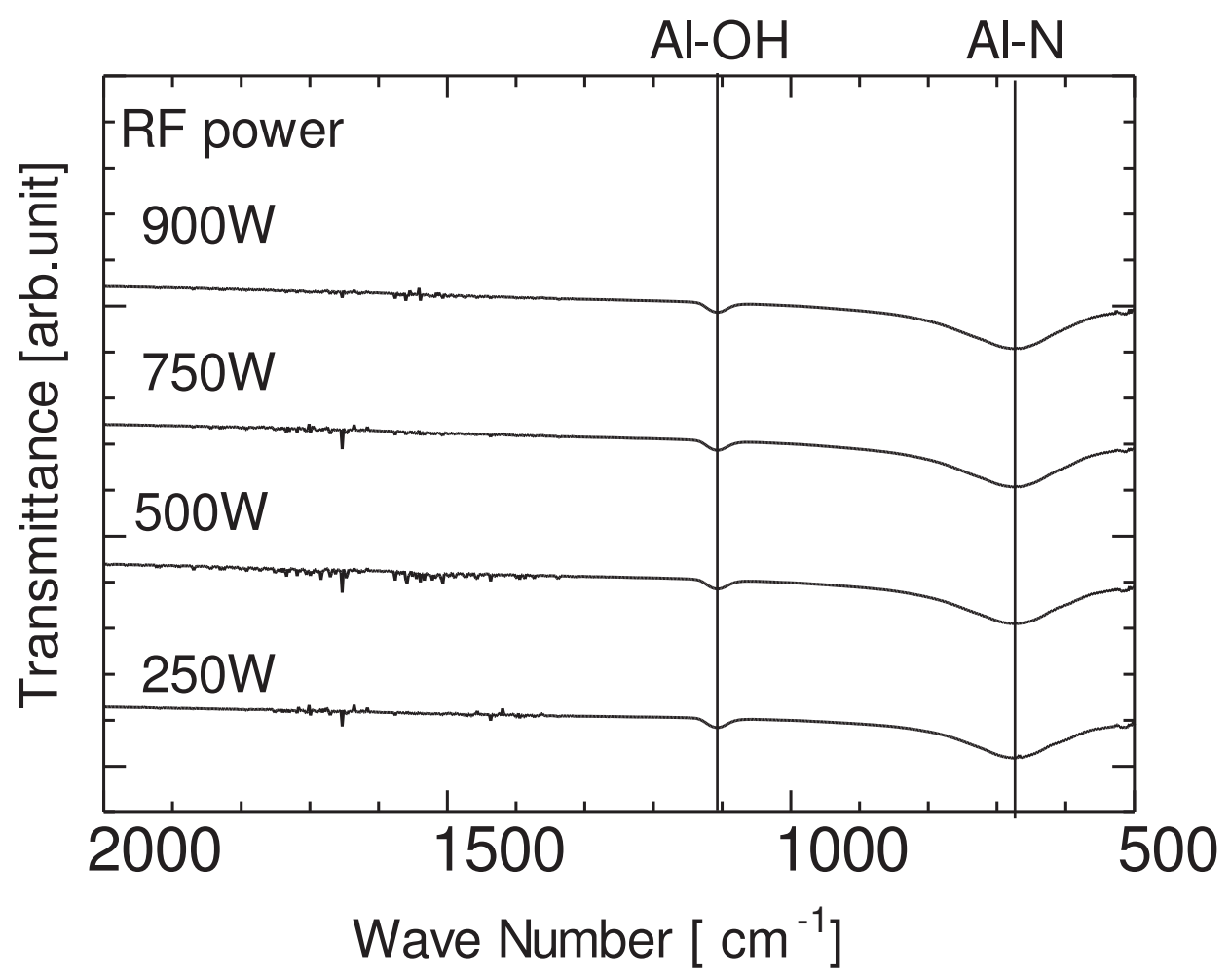


Fig. 5

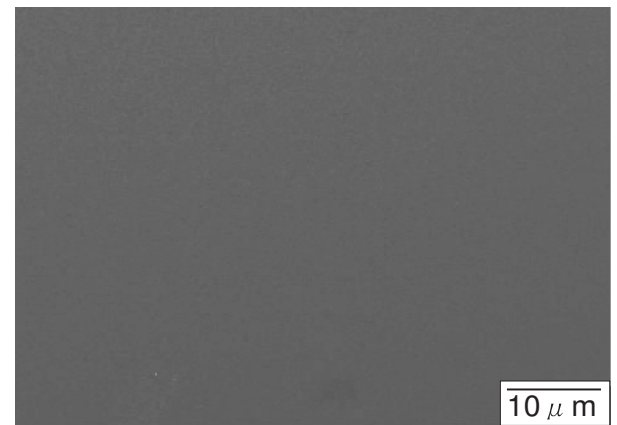

(a) $\mathrm{Al}_{2} \mathrm{O}_{3} / \mathrm{Cu}$ film/glass substrate

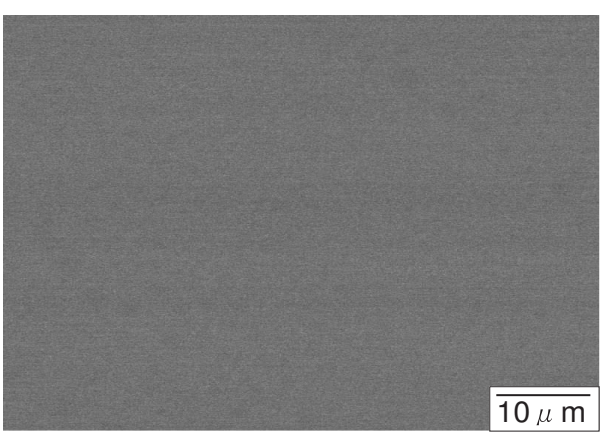

(c) Cu film/glass substrate

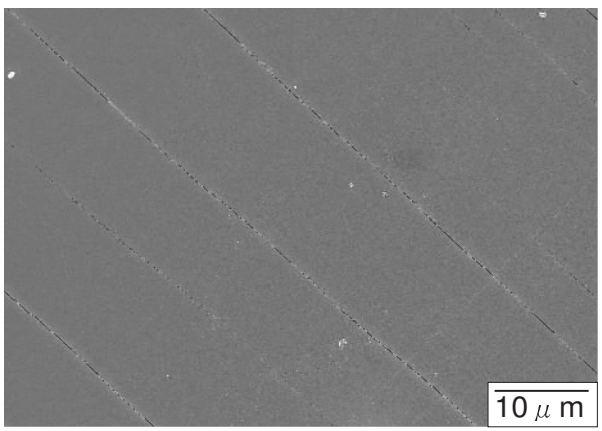

(b) $\mathrm{Al}_{2} \mathrm{O}_{3} / \mathrm{Cu}$ bulk substrate

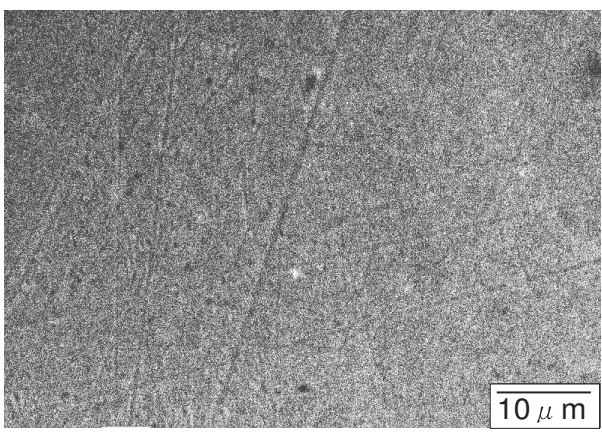

(d) Cu bulk substrate 
Fig. 6
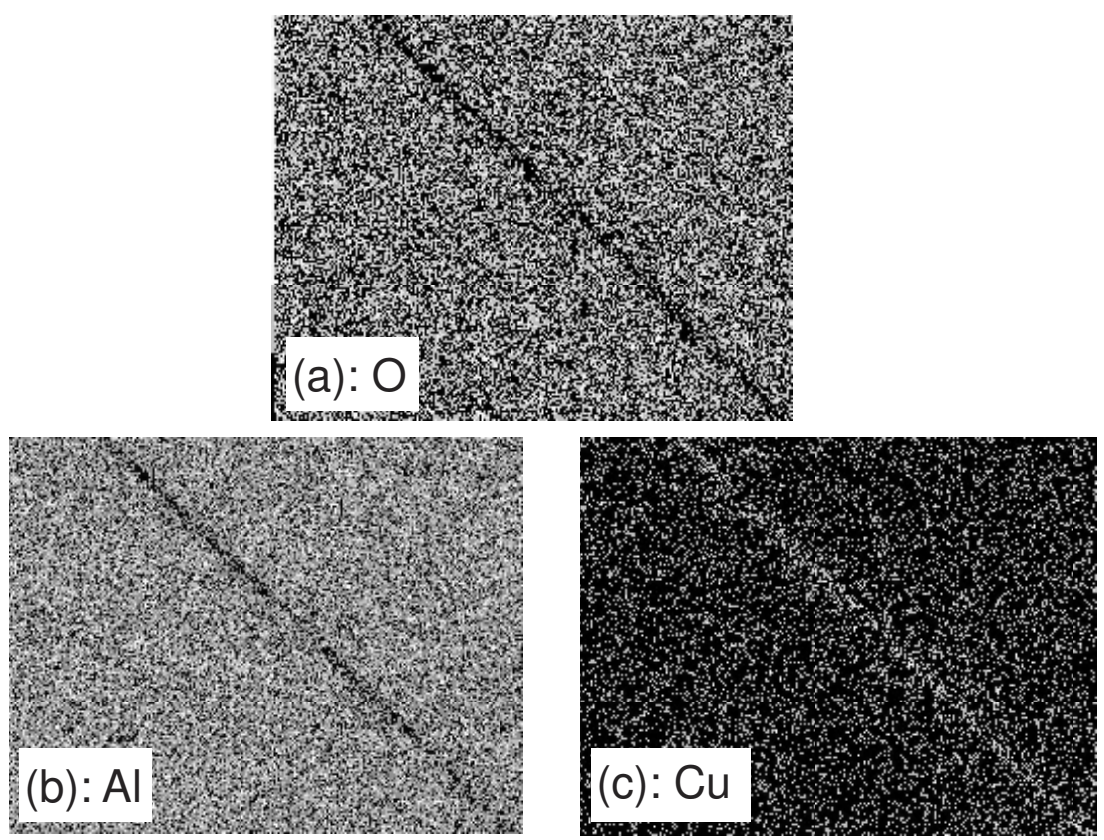